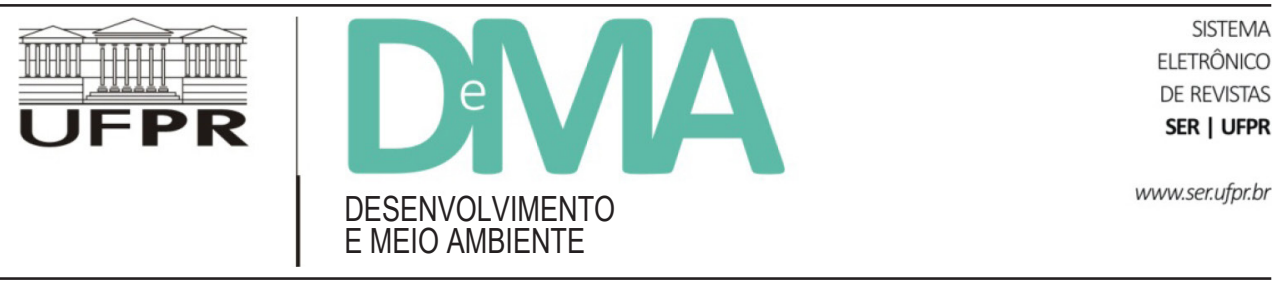

\title{
A paisagem como fenômeno e objeto de interesse público: com que direito? ${ }^{1}$
}

\section{Landscape as a Phenomenon and Object of Public Interest: By What Right?}

\author{
Fábio Christiano Cavalcanti GONÇALVES ${ }^{1 *}$ \\ ${ }^{1}$ Programa de Pós-Graduação em Desenvolvimento Urbano, Universidade Federal de Pernambuco (UFPE), Recife, PE, Brasil. \\ *E-mail de contato: fcantig@yahoo.com.br
}

Artigo recebido em 7 de janeiro de 2015, versão final aceita em 22 de junho de 2015.

RESUMO Objetiva-se discutir a paisagem das cidades como fenômeno e objeto de interesse público comum ao conjunto de uma comunidade ou sociedade, evidenciando-a como tema do direito, na perspectiva de inserir a questão no âmbito de uma política pública específica. Primeiro reflete-se sobre questões que envolvem a relação contemporânea "ser humano-natureza-cidade", na qual se denota uma crise ético-política do Estado, no que tange a uma crise de representação envolvendo direitos fundamentais constitucionais, acompanhada de perto por uma crise ambiental de ampla escala, na qual a paisagem se evidencia como resultante, refletindo o crescente processo de fragmentação sociopolítica. Conjectura-se, a partir disso, a paisagem como problema de interesse público, na perspectiva do "meio ambiente ecologicamente equilibrado". Discute-se, por fim, sobre os documentos emergentes, em âmbito nacional e internacional, que propõem políticas públicas específicas de paisagem, verificando-se o alcance de suas proposições. Como conclusão e em resposta à provocação enunciada pelo título deste trabalho, constata-se: que a paisagem das cidades, no contexto da modernidade, tem sido negligenciada pelo Estado; que o princípio da supremacia do interesse público, como lógica republicana, se encontra invertido na atualidade, em razão da preponderância do interesse privado (sobre o público) nos processos de desenvolvimento urbano; e que a paisagem, como fenômeno e objeto de interesse público, ao ser explicitada a partir da dimensão sociopolítica da cidade, instrumentaliza a formulação de uma política pública específica de paisagem, no contexto das políticas de desenvolvimento urbano no Brasil.

Palavras-chave: paisagem; interesse público; política pública.

ABSTRACT This article aims at discussing the city's landscape as a phenomenon and object of public interest, emphasizing it as a law theme, in view to establish it as a specific public policy for urban development. At first, it explores issues involving the contemporary "human-nature-city" relationship, as an indicator of an ethical-political crisis of the State, which reflects a representation crisis involving fundamental constitutional rights closely connected to a wide-range environmental crisis. It argues that the ever-increasing process of socio-political fragmentation of

\footnotetext{
${ }^{1}$ A presente reflexão integra pesquisa de doutorado intitulada “A paisagem como Res Publica”, ora em elaboração no Programa de Pós-Graduação em Desenvolvimento Urbano (MDU) da Universidade Federal de Pernambuco (UFPE), contando com financiamento do CNPq.
} 
the city has consequences on the landscape and explores it as a public interest issue, in view of an "ecologically balanced environment". Finally, it reviews some emerging national and international documents that propose landscape public policies, evaluating the scope of their proposals.In conclusion, and in response to the provocation laid by its title, the article points out that: the cities' landscape, in modernity context, has been neglected by the State; the principle of public interest supremacy, as a republic's logic, has been nowadays inverted due to the sovereignty of private (over public) interests in urban development processes; and lastly, landscape is instrumental in public policy making considering the sociopolitical dimension of the city - where landscape is a phenomenon and object of public interest - in the context of policies for urban development in Brazil.

Keywords: landscape; public interest; public policy.

\section{Introdução: problematizando a paisagem como tema de interesse público}

Discute-se neste artigo a paisagem como fenômeno e objeto de interesse público comum ao conjunto de uma comunidade ou sociedade, evidenciando-a como tema do direito. Isso é motivado pela observação de que a paisagem, como fenômeno sociopolítico da realidade na cidade, tem sido flagrantemente negligenciada pelos agentes políticos, pela sociedade em geral e pelo Estado, enquanto objeto de interesse da coletividade, como um bem comum e indivisível.

Na verdade, verifica-se que tal problemática se insere em outra dimensão, de maior espectro, relativa a uma crise ética e política do Estado, no que tange a uma crise de representação envolvendo os direitos constitucionais, acompanhada de perto por uma crise ambiental de ampla escala (local e global), na qual a paisagem se evidencia como resultante de um crescente processo de fragmentação socioespacial, refletindo a fragmentação sociopolítica que caracteriza a cidade no atual contexto da modernidade.

Intui-se que tal fragmentação é produto de uma complexa relação historicamente determinada entre o ser humano, a natureza e a cidade, em que há conflitos, na produção desta última, no que diz respeito à natureza como sujeito (determinante) e como objeto (determinado). Acredita-se que,

na verdade, a natureza é a primeira mediação humana para a produção, o primeiro valor da economia, a primeira apropriação, a base de qualquer transformação. Ainda que se perceba que a apropriação da natureza pelo homem é inerente à vida do homem na Terra, em geral não se discute as modificações causadas ao meio ambiente pelas ações econômicas, nem tampouco suas repercussões no sistema econômico, em que pese a importância dessa compreensão para o melhor tratamento das questões econômicas e das graves questões ambientais que se colocam na sociedade moderna (Duarte, 2004, p. 517).

Preceitua-se então que a crise da qual se fala está relacionada a um projeto individualista de mundo, no qual a economia assume papel preponderante, privilegiando-se assim a construção de uma "cidade econômica" em detrimento de uma "cidade social"conforme expressões cunhadas por Milton Santos (2013).

Essa perspectiva é a mesma que defende que: "tudo tem que ser viável economicamente, tudo tem que trazer riqueza, mesmo que as consequências sejam drásticas para o meio ambiente e tragam prejuízos às pessoas" (Fagúndez, 2004, p. 216-217):

como destaca Derani [Cristiane Derani], evidente é o antagonismo entre ecologia e economia, pois, enquanto a ecologia se assenta em uma descrição de tempo e espaço, e os processos de transformação de matéria-prima se exercem sobre um conjunto finito de recursos naturais, a economia não considera as noções de tempo e espaço, considerando os recursos naturais como infinitos e inesgotáveis, justificando a necessidade de um contínuo crescimento, revelado por uma incessante geração de valor, concebida como o início e a finalidade de todo processo produtivo (Duarte, 2004, p.517).

Considera-se então que toda essa crise, conforme Duarte (2004, p. 507), não é propriamente do ambiente, mas dos valores da sociedade e da ética do Estado. 
Não é difícil de ilustrar o que se fala. O tratamento que vem sendo dado às cidades, a partir de um planejamento de matriz racionalista e de viés instrumental-legal fundada na lógica da propriedade privada, termina por caracterizar um desarraigamento do ser social de seu meio, uma vez que:

é fácil observar que os agrupamentos humanos, numa sociedade regida pela prevalência da propriedade privada, constroem cenários urbanos marcados pela desordem visual, provocada pelo acúmulo de objetos desconectados, sejam eles anúncios comerciais, sinais de trânsito, de obras públicas, postes, fios, antenas, faixas, tapumes e mesmo prédios deslocados. O resultado é um cansativo conjunto desarmônico, que forma uma paisagem urbana degradada, compulsoriamente colocada no campo visual da coletividade. É evidente, por outro lado, a consequente descaracterização do aspecto urbano (Jorge \& Gentil, 2009, p. 2297).

Dessa forma, sugere-se debater aqui a emergência da paisagem como fenômeno e objeto de interesse público, como problema político e como assunto de uma política pública específica, considerando que as "paisagens foram inicialmente compreendidas como matéria, e gradualmente tornaram-se objeto social e histórico. Hoje, paisagem pertence ao campo das políticas públicas e da cidadania" (Sauter et al., 2008, p. 1)2.

Parte-se da constatação de que "a maior parte das políticas públicas incidentes sobre a paisagem tem uma visão redutora das dinâmicas que estão associadas às suas alterações e mutações" (Roca \& Oliveira, 2010, p. 10), uma vez que "[...] a ação do Estado brasileiro autoritário privilegiou a ocupação, marginalizando a estrutura ambiental, em poder e em recursos, como se tivesse sido criada apenas para responder a pressões" (Brasil, 2005, p. 10).

Entretanto ainda que o tema do meio ambiente, como tratado pela perspectiva jurídica, proponha uma abordagem ampliada, considerando os meios bióticos e abióticos como partes integrantes de uma totalidade, observa-se na prática política uma crescente negligência quanto à cidade como meio ambiente urbano, como se, enquanto artefato humano, prescindisse de cuidado ambiental. Em contraposição argumenta-se:

quando se fala em proteção legal ao meio ambiente a primeira ideia que surge é a de tutelar os recursos naturais. Embora seja nesse sentido a maior parte do discurso ambientalista - engajado na preservação da flora, fauna, água e ar - a paisagem urbana, como parte integrante do meio ambiente, é também um interesse a ser resguardado (Jorge \& Gentil, 2009, p. 3002).

Importa então ratificar que o "[...] meio ambiente deixa-se conceituar como um espaço onde se encontram os recursos naturais, inclusive aqueles já reproduzidos (transformados) ou degenerados (poluídos) como no caso do meio ambiente urbano" (Derani, 1997, p. 7071). Nesse ponto, corrobora-se então com a visão de Duarte (2004):

o fato é que quando se começa a estudar e aplicar a legislação ambiental há um grande risco de visualizar o meio ambiente a partir de sua concepção restrita - limitada à defesa dos recursos naturais e sem qualquer contextualização - o que não mais se coaduna com as exigências da sociedade contemporânea, na qual os problemas estritamente ambientais estão interligados com tantos outros (reflexamente ambientais) que influem decisivamente no tratamento daqueles (Duarte, 2004, p. 513).

Assim, configura-se que o conceito de meio ambiente não pode ser pensado de forma dissociada de toda a base social que o envolve, onde o ser humano se apresenta como sujeito determinante e determinado nessa relação.

Ressaltamos que não nos interessa investir na tipificação classificatória do termo, separando-o como o fazem, por questões didáticas e, acredita-se, para a

\footnotetext{
${ }^{2}$ Tradução do autor, do texto original: "landscapes were initially understood as a materiality, and gradually became a social and historical object. Today, landscape belongs to the field of public policies and citizenship" (Sauter et al., 2008, p. 1).
} 
facilitação da prática jurídica, em meio ambiente natural, meio ambiente artificial e meio ambiente cultural. Isso porque o foco de reflexão deste artigo é a paisagem como fenômeno e objeto de interesse público, discutindo-se na perspectiva do direito ao meio ambiente ecologicamente equilibrado na cidade em sua totalidade.

Para isso trazemos a definição oferecida pela Declaração de Estocolmo (1972) ${ }^{3}$, que bem se apresenta como base para se pensar o meio ambiente em toda a sua complexidade:

o homem tem o direito fundamental à liberdade, à igualdade, e ao desfrute das condições de vida adequadas em um meio de qualidade tal que the permita levar uma vida digna e gozar de bem-estar e tem a solene obrigação de proteger e melhorar o meio para as gerações presentes e futuras.

Argumenta-se ainda que "os problemas da sociedade contemporânea já não se contentam com um tratamento limitado e parcializado, mas exigem a percepção de todos os fatores que com eles se relacionam, sejam eles econômicos, políticos, sociais ou culturais" (Duarte, 2004, p. 511).

Tal atitude, por vezes, tem gerado, segundo Leite (2004), uma inadequação e ineficácia na proteção ao meio ambiente. De uma forma global, considera-se que mais do que estritamente a proteção da natureza, dos recursos naturais, o desafio que se coloca é a "[...] busca do equilíbrio entre as polaridades e contradições existentes na civilização já que, em última análise, estas são as verdadeiras causas da crise ecológica" (Duarte, 2004, p. 512-513). Nesse contexto, fica claro o seguinte:

é certo que inexiste um sistema autônomo de proteção jurídica à paisagem urbana. Mas isso não significa a inexistência de uma tutela ao direito à paisagem. Tanto é assim que a legislação nacional vigente traz diversas referências ao termo ou às suas variações. De maneira geral, fica a impressão de que há certa insuficiência no tratamento legal do tema, além de timidez do intérprete para alargar, na prática, o sentido das normas existentes (Jorge \& Gentil, 2009, p. 3004).

Diante do exposto, este artigo tem por objetivo problematizar a paisagem como fenômeno sociopolítico, objeto de interesse público e um direito de coletividades, na perspectiva de contribuir para o debate sobre a formulação de políticas públicas de desenvolvimento urbano.

Para tanto, parte-se para a discussão do tema, em que inicialmente apresentamos uma breve reflexão sobre a percepção da paisagem no contexto da cidade na modernidade, a partir da consideração de sua dimensão sociopolítica. Ressalva-se que essa abordagem não se faz pela perspectiva da estética urbana, mas investe-se na consideração da paisagem como produto e produtora/ mediadora das relações sociais, refletindo-se sobre a fragmentação social no espaço da cidade, na forma de percepção de suas paisagens.

Tal pressuposto constitui então um lastro mínimo para se pensar a articulação entre a noção de paisagem, como dimensão sociopolítica da cidade, e a noção de interesse público, encadeando os termos a fim de se chegar à consideração sobre como a paisagem pode ser concebida como bem comum, de coletividades, e assim instrumentalizar uma política pública específica, no contexto das políticas de desenvolvimento urbano no Brasil.

\section{A paisagem como processo e produto da inter- relação "natureza-ser humano-cidade"}

Importa desenvolver, preliminarmente, o entendimento da noção de paisagem, apoiando-se nas abordagens oferecidas por Augustin Berque e George Simmel. Berque (1998) defende que para compreender a paisagem se faz necessário conhecer as determinações culturais, sociais e históricas da percepção - o que constitui a subjetividade humana, indo além da configuração morfológica dos componentes do ambiente.

${ }^{3}$ Declaração realizada em Estocolmo pela Organização das Nações Unidas para o Meio Ambiente, entre 5-16 de junho de 1972. Disponível em: portal.iphan.gov.br/portal/baixaFcdAnexo.do?id=243. Acesso em: 05.01.2015. 
Essa subjetividade humana, como ato cognitivo do ser humano na configuração de uma paisagem, pode ser bem compreendida a partir do preconizado por Simmel (2009), ao conceber que ao recortar da natureza um fragmento, o sujeito o faz por meio de um processo em que o conjunto de objetos contidos nesse excerto são inter-relacionados pelo intelecto, constituindo um novo conjunto, ou melhor, uma nova totalidade, que se entende por paisagem.

Assim, explicita que não é a mera configuração morfológica como um conjunto de objetos isolados no espaço, que constitui uma paisagem - como uma fotografia produzida a partir do que o campo visual humano conseguiu abarcar em um lance de vista. Mas, tão somente, quando nesse processo (em que todos os sentidos atuam integradamente) os diversos elementos são rearranjados de forma tal que se reapresentam como uma nova unidade, a partir de um "para-si", ou seja, de uma relação de identificação entre esse novo conjunto e o indivíduo que o concebeu.

Nessa direção, Serrão (2013) explica:

[...] a "paisagem" só surge quando a vida pulsando na intuição e no sentimento é em geral arrancada à unicidade da natureza e o produto particular assim criado, transferido para um estrato inteiramente novo, se reabre então, por assim dizer, de per si à vida universal, acolhendo o ilimitado nos seus limites inviolados (Serrão, 2013, p. 8).

Dessa maneira, pensar a paisagem como superfície permeada de sensibilidades, como "[...] dimensão da realidade ou do Ser" (Serrão, 2013, p. 170), nos leva a considerar o corpo humano como elemento mediador e relacional, enquanto corporeidade, com valor suprassensível, utilizando-se de toda a potencialidade cinestésica que o constitui e que conforma também toda a sua exterioridade - o mundo em que habita.

Entretanto o estabelecimento da corporeidade como unidade relacional enfrenta a separação entre o ser humano e Terra:

a cisão com a dimensão relacional da existência, separando o espírito humano da Terra, ou noutros termos, o subjectivo do objectivo, estaria associada até hoje à ideia de progresso e ao modelo de crescimento econômico que afecta profundamente a atitude para com o mundo envolvente e igualmente a esfera social (Serrão, 2013, p. 163).

Compreende-se então que a paisagem se constitui em uma forma de ver o mundo, sendo agenciada a partir de um conjunto de valores que o indivíduo traz consigo e lhe atribui. Então, a paisagem reflete os valores do indivíduo e assim os da sociedade que integra, e assim evidencia no contexto atual, em geral, a lógica individualista que caracteriza desde então o apartamento do ser humano em relação à natureza, quando sobrepõe suas vontades aos demais seres viventes.

Diante do exposto, consideramos que a noção de "paisagem" pode ser uma chave importante para refletir sobre a relação "natureza-ser humano-cidade" na contemporaneidade, por ser um meio de revelação de uma forma de vida calcada em determinados valores socialmente estabelecidos, como nos indica Ost (1995):

a questão da paisagem (essa bela palavra que parece resultar da sobreposição de "país" e "imagem") pode servir aqui de paradigma: pois não é, indistintamente, realidade física e produto social? Enquanto resultado, em constante transformação, dos costumes sociais de um determinado local, a paisagem evolui entre natureza e sociedade; ela é simultaneamente natureza-objecto e natureza-sujeito (Ost, 1995, p. 16-17).

Assim, propõe-se que pensar a paisagem da cidade requer uma reflexão sobre o processo de subjetivação e de objetivação da natureza, que se processou historicamente. Para isso é importante considerar que esse processo é passível de ser lido e compreendido no espaço da cidade, e aparece refletido na paisagem o comportamento dos sujeitos sociais diante da natureza transformada em artifício (cidade). Sujeitos estes que, por vezes, acabam por naturalizar o artifício criado (cidade) como se fosse algo imanente a sua condição. De qualquer forma, com a cidade (re)cria-se uma natureza, não em sua condição in natura, mas como cultura.

A cidade como uma nova natureza, ao combinar elementos naturais e artificiais que lhe constitui, estabelece assim uma relação de interdependência que é 
preciso observar. Se por um lado há uma tentativa de controle absoluto do sujeito sobre o meio ambiente que o cerca, o ambiente continua imprimindo sua condição de existência e em alguma medida estabelecendo alguns limites imprescindíveis para a própria continuidade da cidade como lócus de morada humana, na qualidade de espaço político por excelência.

No entanto foi propriamente nos termos de uma "natureza-objeto" que, segundo Ost (1995, p. 10), "a modernidade ocidental transformou a natureza em 'ambiente': simples cenário no centro do qual reina o, que se autoproclama, 'dono e senhor'." Em razão disso, é condicionada sua redução a um "simples reservatório de recursos", à disposição do ser humano para seu ilimitado desfrute, tornando-se ainda um mero depósito de resíduos, ou seja, o meio ambiente como "o pátio das traseiras da nossa tecnosfera" (Ost, 1995, p. 10).

Esse contexto é o que vem marcar a história da humanidade na modernidade, caracterizando-se pela ruptura entre o ser humano e o seu entorno imediato, ou seja, com o meio que o rodeia, proveniente da "mecanização do Planeta", como estratégia de dominação (Santos, 1992, p. 4).

Segundo Ost (1995, p. 15), podemos entender que tal posicionamento funda a cisão entre o naturalismo e antropomorfismo, vindo a caracterizar a clivagem dos defensores da "natureza-sujeito" pela deep ecology, quando a natureza assume a posição de "norma de conhecimento e regra de ação" contra a "natureza-objeto", reflexo do extremo utilitarismo do pensamento da modernidade, no qual o sujeito projeta, de forma onipotente, sua visão sobre as coisas.

Essa separação coloca o sujeito em uma posição em que ele não se enxerga como parte desse meio, mas apartado de tudo e de todos, vindo a "[...] perceber o mundo como uma coisa separada dele por um abismo, como o "objeto"” (Elias, 1994, p. 53).

Esse parece ser o caminho trilhado pela sociedade ocidental na contemporaneidade, a qual se mostra cada vez mais exacerbada em seus propósitos privatistas, à mercê de garantir cada vez mais espaço ao "capitalismo parasitário", que suga todos os recursos disponíveis até a morte do "hospedeiro", como Bauman (2010) ilustra.
Nisso se discute o poder destruidor do ser humano sobre o meio ambiente, transformando tudo o que é "sólido" em "fluidos". Tal poder pode ser caracterizado pelo que Berque (1998, p. 11) denomina de "tríplice objetivação moderna - a do corpo, a das pessoas e a do ambiente", cindindo assim o mundo em partes quase que irreconciliáveis, marcando definitivamente na história uma nova direção na relação entre o ser humano e a natureza.

Essa postura é identificada como típica do comportamento do indivíduo nas grandes cidades, uma vez que "a atitude que poderíamos chamar prosaicista está obviamente tão intimamente inter-relacionada com a economia do dinheiro, que é dominante na metrópole, [...]", como disse Simmel (1973, p. 14).

É nesse ínterim que podemos compreender a assertiva de Berman (1986), ao refletir sobre tais implicações:

o eclipse do problema da modernidade nos anos 70 significou a destruição de uma forma vital de espaço público. Acelerou a desintegração do nosso mundo em um aglomerado de grupos de interesse privado, material e espiritual, vivendo em mônadas sem janelas, ainda mais isolados do que precisamos ser" (Berman, 1986, p. 32-33).

É esse cenário que fará o espaço desaparecer gradualmente, e com ele as relações sociais, porque o sujeito se encontra desterritorializado, fora de seu locus, de sua sólida morada, porque imerso no fluido dos contatos virtualizados, fomentando-se a antinomia entre o ser individual e o ser social, apartando o indivíduo da sociedade.

Assim, chega-se ao entendimento de que a paisagem, como categoria do pensamento, se institui enquanto fenômeno e objeto revestido de concreticidade, porque traz em si mais do que o reflexo da sociedade que espelha, como produto social, se apresentando como a própria sociedade expressa em seus modos, crenças, valores: "Com base nisso é possível compreender a realidade social pelo prisma das 'forças socializantes da natureza', ou seja, pelo modo como cada sociedade se apropria dos recursos naturais e transforma o ambiente em que vive" (Derani, 1997, p. 68-69). É nesses termos que se compreende a produção social como natural (natureza socializada): 
Natureza é a primeira mediação humana para a produção. A produção social é uma produção natural, posto que o homem, em qualquer formação social, tem as relações de produção e reprodução social mediadas pela natureza. A base e os limites dos objetivos da atividade humana são determinados pela prática social - pelos elementos históricos, culturais e naturais que integram cada sociedade. A produção é sempre social. Ela é sempre apropriação da natureza pelo indivíduo no interior e mediada por uma determinada forma de sociedade, conclui Alfred Schmidt (Der Begriff der Natur in der Lehre von Marx, p. 57, apud Derani, 1997, p. 117).

Dessa forma, sugere-se pensar que a paisagem das cidades revela a constituição da própria sociedade e que nesses termos deve ser objeto de cuidado pelo Estado. Explica-se como meio de compreensão de sua constituição (da sociedade por meio da paisagem) e, mais concretamente, para se dirigir uma ação consciente de planejamento das cidades, como um objeto que está diretamente relacionado à sociedade que a constitui e assim passível de ser admitida como um direito da coletividade.

Nessa direção, encontra-se apoio em Antônio Zanollo Neto, quando explicita que:

adquirir conhecimento por meio dos sentidos para formar a ideia da necessidade de tutela da paisagem como elemento do direito ambiental é desafiante tanto para o Poder Público como para a coletividade, pois a paisagem é e será sempre uma experiência humana que depende da realidade concebida pelos olhos dos que a veem, sendo determinada pelos valores e cultura da pessoa ou coletividade que a avaliam (Neto, 2010, p. 30).

Falar da paisagem na perspectiva do direito implica primeiramente evidenciar que ela se apresenta, em geral, como tema de fundo das discussões sobre a qualidade do meio ambiente, a despeito de se encontrar em crescente processo de fragmentação, a ponto de comprometer, ou mesmo impedir, o estabelecimento de qualquer relação de identificação dos citadinos com a cidade, porque destituída de sentido enquanto locus relacional sociopolítico.

Essa perspectiva nos dá as chaves para compreender a paisagem como objeto de interesse público.

\section{A paisagem como objeto de interesse público primário}

A fim de refletir sobre a condição da paisagem enquanto objeto socialmente constituído intersubjetivamente pela percepção humana, por meio da qual se estabelece uma relação de identificação do ser humano enquanto ser social, confronta-se com a condição posta na modernidade, marcada pelo distanciamento entre as esferas do indivíduo e da sociedade. Por outro lado, passa-se a refletir sobre outro duplo dialético, as categorias público e privado, aparentemente contraditórias. Pela interpenetração de tais entendimentos, se perscruta o princípio do interesse público, na medida em que

este impasse coloca-nos o desafio da coordenação das práticas individuais com os interesses coletivos. É por isso que a questão da apropriação dos recursos naturais tem a vocação de chamar à revisão das clássicas dicotomias (público-privado, estado-sociedade, economia-ecologia), que, na verdade, sempre se constituíram como revelações alternadas do todo indissociável (Derani, 1997, p. 118; grifo original).

Partimos da seguinte assertiva: "interesse público é termo de conceito indeterminado, logo interesse digno de ser interpretado" (Carmo, 2000, p. 31). Tal exposição já se coloca para debate, a partir de processo interpretativo, porque variável de acordo com o contexto social onde é pensado. Nesse caminho, destaca-se como importante “[...] a lição de Silva, para o qual o interesse público não é um dado, mas é construído por todos com a participação do Estado" (Duarte, 2004, p. 516).

Um primeiro vínculo aí se estabelece, apresentando-se o Estado e a sociedade como atores imprescindíveis no âmbito do interesse público, da coisa pública.

No que tange ao contexto da Cidade e particularmente a partir da percepção da paisagem, pode-se evidenciar o reflexo da postura privatista sobre os bens que a constituem, considerando que

há uma particularidade nessa situação: os objetos, cujas imagens são projetadas no campo visual do observa- 
dor, constituem, na sua maioria, domínio privado dos proprietários dos bens móveis ou imóveis que estão instalados no local. Dessa maneira, sem o desejar, cada proprietário, por intermédio da ação que empreende nos seus próprios domínios, concorre para formar o desenho final da paisagem, a qual, diversamente do que ocorre com o uso dos bens privados, está disponível para toda a coletividade. É assim possível dizer que, de certo modo, essa coletividade, formada pelo número indeterminado de observadores, frui de um bem que, sendo diferente dos bens individualmente considerados, é composto involuntariamente pela atividade de proprietários privados (Jorge \& Gentil, 2009, p. 3000-3001).

Propõe-se então aqui reconhecer a existência de uma dimensão da paisagem que está no âmbito do interesse público, enquanto fenômeno e elemento comum à percepção coletiva, e de direito dos cidadãos, mas que tem sido "esquecida" como tal no processo de planejamento e desenvolvimento das cidades, das regiões e dos territórios, apresentando-se como uma dimensão não institucionalizada e subvalorizada nas arenas de decisões políticas formalmente constituídas, fazendo-se presente, no mais das vezes, apenas como pano de fundo das disputas econômicas.

Primeiro, no que tange à dicotomia praticada entre indivíduo e sociedade postula-se, de acordo com Derani, que não se pode entender a sociedade como mera convenção de indivíduos, mas, "ao contrário, é a sociedade-comunidade um estar-com-o-outro e pelo-outro. Pessoas são ligadas por laços menos conscientes, tais como terra, cultura, destinos, atuação conjunta e interdependente" (Derani, 1997, p. 50).

Dessa assertiva, e compreendendo-se o desenvolvimento da argumentação da autora, destaca-se que a sociedade não é um "agrupamento aleatório humano", mas constituição de seres individuais enquanto seres sociais, por meio dos quais se estabelecem laços de solidarização em razão de objetivos comuns, enfatizando-se que "desta união desenvolve-se a existência individual. Basta lembrar que o Eu e a sociedade somente existem e permanecem à medida que se nutrem um ao outro" (Derani, 1997, p. 50).

No cerne dessa discussão, é oportuno enfatizar que em suas bases ideológicas o princípio do interesse público não se compreende desvinculado da noção de interesse privado, contrapondo-se à ideia matriz corrente de que " $[. .$.$] o que pertence a todos não pertence a nin-$ guém e a constatação de que há uma tendência das pessoas de se preocupar com a preservação e a manutenção de bens que lhes pertençam em grau infinitamente maior do que com os bens que não estão sob o seu domínio" (Duarte, 2004, p. 519).

Chama-se atenção para a correlação aqui trazida, a partir de Carmo (2000), entre interesse público e interesse difuso, da qual posteriormente se fará um retorno.

A emergência de uma explicitação da noção de interesse público, consensuada na doutrina, segundo Mazzilli (2007), pode ser explicitada em razão de que a clássica dicotomia entre interesse público e interesse privado dentro da tradição do direito romano passa a ser questionada. Para tanto, o autor apresenta as seguintes razões:

\begin{abstract}
em primeiro lugar, porque hoje a expressão interesse público tornou-se equívoca, quando passou a ser utilizada para alcançar também os chamados interesses sociais, as interesses indisponíveis do indivíduo e da coletividade, e até os interesses coletivos ou os interesses difusos etc. [...]. Em segundo lugar, porque, nos últimos anos, tem-se reconhecido que existe uma categoria intermediária de interesses que, embora não sejam propriamente estatais, são mais que meramente individuais, porque são compartilhados por grupos, classes ou categorias de pessoas [...] (Mazzilli, 2007, p. 46).
\end{abstract}

Nesse sentido, compreende-se que a noção de interesse público se apreende aplicável de uma forma mais abrangente, para além dos conflitos de interesses entre Estado e Sociedade, ou entre indivíduos, para representar uma via intermediária do direito, de espectro social, abarcando um conjunto de pessoas, uma determinada coletividade.

Não obstante, a dificuldade para a doutrina clássica admitir uma terceira via no direito, Mazzilli (2007), com o objetivo de melhor explicitar o entendimento que o Brasil vem construindo sobre o tema, principalmente a partir de seu aporte constitucional, aborda tal conjunto de interesses com base na Lei n. 7.347/85 - Lei de Ação Civil Pública, e na Lei n. 8.078/90 - Código de Defesa do Consumidor. Assim, subdivide o que chama de inte- 
resses transindividuais em: interesses difusos, interesses coletivos e em interesses individuais homogêneos.

Tais grupos se diferenciam entre si em termos de escala e forma de representação, além de se constituir em subconjuntos, derivados do interesse público mais abrangente. É assim que Mazzilli esclarece a posição de Renato Alessi, ao propor uma distinção entre "interesse público primário" - o relativo ao interesse da coletividade como um todo - e o "interesse público secundário" - referente ao "modo pelo qual os órgãos da administração veem o interesse público" (Mazzilli, 2007, p. 47), explicando com o que segue:

há, pois, interesses que envolvem uma categoria determinável de pessoas (como os interesses individuais homogêneos e os interesses coletivos); outros, são compartilhados por grupo indeterminável de indivíduos ou por grupo cujos integrantes são de difícil ou praticamente impossível determinação (como os interesses difusos) (Mazzilli, 2007, p. 49; grifo original).

Entretanto deixa nítida sua posição quanto a essa forma de compreender a representatividade do interesse público, a mesma adotada no presente artigo, explicitando que: "sem negar, porém, o caráter da conflituosidade normalmente inato na discussão dos interesses transindividuais, de nossa parte, cremos ainda na supremacia da noção de bem comum, ou seja, o de interesse público primário" (Mazzilli, 2007, p. 48).

Entende-se que essa posição se apresenta como a mais equilibrada, ao não abrir mão da existência de um bem coletivo que é superior aos interesses em conflito, sem que seja possível fazer escolhas ou dividi-lo a partir de grupos de indivíduos isoladamente, ainda que se admita que sempre existirão disputas, considerando-se inclusive a complexidade da sociedade na contemporaneidade, com tantas demandas latentes e com tão poucas soluções postas em curso para atendê-las.
Entretanto cabe, sem dúvida, fazer aqui um destaque à categoria dos "interesses difusos". Se retomarmos a referência trazida de Carmo $(2000)^{4}$, pode-se intuir que o autor não faz distinção aparente com a noção de interesse público em sua totalidade, denominada por Renato Alessi, conforme Mazzilli (2007), como "interesse público primário", conforme visto. Ou seja, as noções de interesse público e interesse difuso se confundem, o que parece ser muito recorrente nos textos que trazem tais sentidos como sinônimos. Porém Mazzilli procura destacar bem essa última noção:

Os interesses difusos compreendem grupos menos determinados de pessoas (melhor do que pessoas indeterminadas, são antes pessoas indetermináveis), entre as quais inexiste vínculo jurídico ou fato preciso. São como um feixe ou conjunto de interesses individuais, de objeto indivisível, compartilhados por pessoas indetermináveis, que se encontram unidas por circunstâncias de fato conexas (Mazzilli, 2007, p. 50).

Contudo a diferença entre interesse difuso e interesse público está no fato de que o primeiro possui, em algum grau, um grupo ou conjunto de indivíduos referencial, unidos por circunstância de fato conexa, ainda que de difícil determinação das pessoas que fazem parte dele, considerando que o direito pleiteado pode não coincidir com o desejado pela coletividade; enquanto no segundo não há a possibilidade da determinação de um grupo em específico, mas se refere a toda a sociedade envolvida, em que o objeto de direito é automaticamente extensível a toda a coletividade de uma sociedade.

Essa diferenciação importa aqui pela relação, quase que imediata, entre os interesses difusos e as questões relacionadas ao meio ambiente. De maneira específica ao tratarmos da paisagem como um bem que, de fato, enquanto fenômeno e objeto de interesse público se apresenta indivisível.

\footnotetext{
${ }^{4}$ Segundo Carmo (2000, p. 24): “Tendo diante as características dos interesses difusos, é possível identificar um conjunto de situações sociais urbanas propícias à revelação de tais interesses. São um corpo variado de circunstâncias de fato, concernentes à coletividade, impossíveis de subjetivação, a título exclusivo, por uma pessoa ou grupo".
} 
Por esse entendimento, pensa-se que a paisagem pode ser compreendida também como objeto de interesse difuso, pela acepção de indeterminação que enseja. No entanto este artigo se ocupa em contribuir para fundar sua dimensão social, como um todo indivisível, comum à coletividade em geral, ainda que admitindo a multiplicidade de interesses - e assim, ratifica-se como oportuna a posição de considerar a paisagem como objeto de interesse público primário ${ }^{5}$.

A partir do exposto anteriormente, passa-se à consideração da paisagem como parte indissociável da estrutura ambiental, porque extensível à sociedade em geral, constituindo-se diretamente a necessidade de alargar o princípio da defesa do meio ambiente no âmbito dos direitos fundamentais previstos pela Constituição Federal de 1988. Verifica-se que esses princípios estão expressos por todo o texto constitucional, para além do artigo $5^{\circ 6}$ que os traz explicitamente. Nesse contexto, é mais particularmente no artigo $225^{7}$, segundo Derani, que se compreende:

de princípio-base da ordem econômica - necessário ao desenvolvimento da atividade econômica - tem seu conteúdo ampliado, quando é reconhecido que, além de um fator da produção, é a conservação do meio ambiente uma condição essencial para o livre desenvolvimento das potencialidades do indivíduo e para a melhoria da convivência social (Derani, 1997, p. 255).

Segundo a autora citada, o meio ambiente se constitui como patrimônio coletivo imprescindível ao indivíduo, no processo de formação de sua personalidade, bem como da sociedade em geral, pelo esta- belecimento de uma relação "social-natural-humana" (Derani, 1997, p. 147). Assim, considera que "o meio ambiente ecologicamente equilibrado é um bem jurídico constitucionalmente protegido. Este bem não pode ser desmembrado em parcelas individuais. Seu desfrute é necessariamente comunitário e reverte ao bem-estar individual" (Derani, 1997, p. 259).

Pelo exposto anteriormente, de forma a evidenciar uma correlação direta entre os direitos fundamentais e o direito ao meio ambiente ecologicamente equilibrado, considera-se que:

pode-se afirmar, com discussões, que o direito à cidade, que tem por conteúdo o bem-estar urbano, em cumprimento à função social da cidade e da propriedade urbana, é um direito social típico, enriquecido de inúmeros outros espalhados no texto constitucional, assumindo, por vezes, a natureza de uma proposição política ou de direito fundamental, que dimensionam e dão consistência à ordem política (Carmo, 2000, p. 23; grifos originais).

Pelo exposto até aqui, e fazendo-se uso das palavras de Fagúndez (2004, p. 211), defende-se que "o que a modernidade deve superar é toda a fragmentação que se operou historicamente".

Acredita-se, então, que só nesse sentido efetivamente se pode pensar na construção de uma política pública de paisagem, que esteja acima do antagonismo estabelecido entre público e privado, entre indivíduo e sociedade. Assim, acredita-se ser possível constituir uma via alternativa à consecução dos princípios, objetivos e direitos fundamentais estabelecidos pela Carta Magna, contribuindo-se

\footnotetext{
${ }^{5}$ Ver: Constituição da República Federativa do Brasil de 1988 (CF 88). Título II - Dos Direitos e Garantias Fundamentais, Capítulo I- Dos Direitos e Deveres Individuais e Coletivos. Disponível em: http://www.planalto.gov.br/ccivil_03/constituicao/constituicaocompilado.htm. Acesso em: 03.01.2015.

${ }^{6}$ Ver: CF 88, Art. 225. "Todos têm direito ao meio ambiente ecologicamente equilibrado, bem de uso comum do povo e essencial à sadia qualidade de vida, impondo-se ao Poder Público e à coletividade o dever de defendê-lo e preservá-lo para as presentes e futuras gerações”. Disponível em: http://www.planalto.gov.br/ccivil_03/constituicao/constituicao.htm. Acesso em: 01.01.2015. Disponível em: http://www. planalto.gov.br/ccivil_03/constituicao/constituicaocompilado.htm. Acesso em: 03.01.2015.

${ }^{7}$ Ver: CF 88, Art. 225. "Todos têm direito ao meio ambiente ecologicamente equilibrado, bem de uso comum do povo e essencial à sadia qualidade de vida, impondo-se ao Poder Público e à coletividade o dever de defendê-lo e preservá-lo para as presentes e futuras gerações". Disponível em: http://www.planalto.gov.br/ccivil_03/constituicao/constituicao.htm. Acesso em: 01.01.2015. Disponível em: http://www. planalto.gov.br/ccivil_03/constituicao/constituicaocompilado.htm. Acesso em: 03.01.2015.
} 
para alcançar a almejada qualidade de vida, nos termos de um "meio ambiente ecologicamente equilibrado", como um direito de todos, indiscriminadamente.

\section{A paisagem como tema de uma política pública específica}

Em primeiro lugar, importa aqui estabelecer o que se entende por política pública. Antes disso, destacamos o sentido do termo "política". Segundo Bobbio a etimologia da palavra política nos leva ao adjetivo que a originou - deriva de pólis (politikós), significando “[...] tudo o que se refere à cidade e, consequentemente, o que é urbano, civil, público, e até mesmo sociável e social [...]". Esse entendimento se apresenta revelador de um sentido que parece ter sido emulado na compreensão atual do que é política, bem como dissociado do que representa a cidade; derivando hoje para expressar uma "[...] forma de saber mais ou menos organizado sobre esse mesmo conjunto de coisas [...]" (Bobbio, 1998, p. 954).

De maneira mais ampliada, o sentido de política se mostra multifacetado, podendo-se dizer que "[...] a esfera da política se refere pelo menos a uma parte dos comportamentos da espécie humana, os comportamentos socialmente organizados, é óbvio, ou devia sê-lo, o nexo existente entre Política e Ecologia" (Bobbio, 1998, p. 976).

Passa-se desse entendimento do termo política à expressão "política pública". Com o adjetivo acrescentado, amplia-se a noção, evidenciando uma função que estabelece um vínculo com a prática política.

Ressalva-se que não é objetivo deste trabalho explorar as variantes conceituais da expressão "política pública" nem lhe oferecer uma definição fechada, mas tão somente o de estabelecer um ponto base para a discussão que se segue.

Para tanto, inicialmente lança-se mão da interpretação oferecida por Howlett et al. (2013), que traz à luz dois reconhecidos autores desse campo de estudo, Thomas Dye e William Jenkins, por meio dos quais se realizam aproximações conceituais referentes à expressão citada, pela complementaridade de suas percepções.

Abordando-se primeiramente Thomas Dye (1972), destaca-se a compreensão de que política pública refere-se a "tudo o que um governo decide fazer ou deixar de fazer" (Dye, 1972 apud Howlett et al., 2013, p. 6). Nessa definição, ainda que bastante simples, estabelece-se nitidamente que o Estado é o agente primário da ação política pela capacidade legitimada de tomar decisões em nome dos cidadãos, de decidir fazer e não fazer algo (decisões positivas e negativas), ainda que adotando-as de forma consciente e deliberada.

Outra explicação sobre a mesma expressão é apresentada por William Jenkins (1978), oferecendo uma visão mais detalhada, como sendo:

um conjunto de decisões inter-relacionadas, tomadas por um ator ou um grupo de atores políticos, e que dizem respeito à seleção de objetivos e dos meios necessários para alcançá-los, dentro de uma situação específica em que o alvo dessas decisões estaria, em princípio, ao alcance desses autores (Jenkis (1978) apud Howlett et al., 2013, p. 8).

Tal definição, conforme destacam Howlett et al. (2013), apresenta como pontos fundamentais a referência ao conteúdo das políticas públicas -como um processo dinâmico, considerando a complexidade dos "subsistemas políticos-administrativos".

Aponta-se para a complementaridade dessas explicações, a partir das quais se pode compreender que as políticas públicas são instrumentos de ação do poder estatal, tomado por atores políticos legitimados como representantes dos interesses da sociedade, e dirigidas à resolução de problemas/demandas apresentadas pelos diversos grupos sociais.

Nesse sentido, objetivando o estabelecimento de uma relação direta entre políticas públicas e espaço, Steinberger (2006) propõe uma noção de "políticas públicas espaciais", explicitando que as políticas públicas estão relacionadas sempre ao espaço, tendo como base 
física o território, onde se efetivam na prática: “[...] supõe-se que a função precípua das políticas públicas nacionais de caráter espacial seja a de propor ações que representem espacialmente os interesses coletivos explícitos ou implícitos em pactos e compromissos"8 (Steinberger, 2006, p. 32).

Assim, as políticas públicas teriam como função precípua resolver os problemas que atingem o interesse público, que espacialmente se encontram representados, não sendo possível negligenciar o espaço onde estão evidenciados, sob o risco de dar causa a tantos outros problemas, como o da fragmentação das cidades no contexto do meio ambiente urbano.

Para tanto, de um ponto de vista mais abrangente, é possível pensar que há relação direta entre os problemas ambientais e as políticas públicas, seja quando estas são tomadas sem levar em conta que há uma realidade mais complexa do que aquela que a tecnocracia consegue enxergar, seja quando não são admitidas políticas públicas corretivas para problemas ambientais existentes, ao considerar que o meio ambiente tem sido visto equivocadamente enquanto mero suporte dos acontecimentos da vida política.

É a partir dessa constatação que se "[...] denota a necessidade de que a problemática ambiental seja considerada nas estratégias de planejamento do Estado brasileiro, partindo-se, entretanto, de uma visão realista, ampliada, sistêmica e global, de uma sociedade espacial e historicamente determinada" (Duarte, 2004, p. 525-526).

Nessa perspectiva, o direito se apresenta como instrumento da sociedade e do Estado indutor de políticas públicas, revelando-se na condição de esfera capaz de articular os princípios constitucionais e a efetivação prática de ações em seu atendimento, articulando instituições, indivíduos e grupos na superação de dicotomias apresentadas, particularmente aquelas que marcam o antagonismo entre desenvolvimento econômico e equilíbrio ambiental, como expõe Derani (1997):

Embora seja tarefa essencial ao direito fixar as linhas das estruturas sociais, ele vem assumindo sempre com maior intensidade uma postura de ordenação de situações conjunturais, o que lhe impregna também uma função de instrumento implementador de políticas públicas, revelando atualmente o lado funcional do direito paralelamente ao seu conteúdo estrutural (Derani, 1997, p. 53; grifos originais).

Dessa forma, entende-se que o reconhecimento da paisagem no âmbito da noção de "meio ambiente ecologicamente equilibrado" e em consonância com os direitos fundamentais trazidos pela CF 88 , pode servir como nexo estruturador de uma política pública de desenvolvimento urbano, vindo a assumir papel central enquanto categoria capaz de integrar, pela expressão sociopolítica que evidencia, o interesse coletivo.

\subsection{A paisagem no âmbito do ordenamento ter- ritorial e do desenvolvimento urbano}

Considerando como objeto de estudo a dimensão pública da paisagem e sua ascensão como problema político, importa ratificar o entendimento de paisagem como fenômeno sociopolítico:

paisagem é agora claramente reconhecida como um essencial componente do planejamento da cidade e do país. Mais do que locais notáveis e belo panorama, a paisagem é considerada como o ambiente no qual se vive, incluindo paisagens ordinárias onde pessoas vivem diariamente, e onde atividades econômicas são realizadas (Sauter et al., 2008, p. 7; tradução nossa) ${ }^{9}$.

\footnotetext{
${ }^{8} \mathrm{~A}$ autora sugere que o espaço é o fundamento das políticas ambientais, territoriais, regionais, urbanas e rurais. Que o espaço não pode ser compreendido como mero palco ou suporte das políticas públicas, como mercadoria, possuindo "poder de determinação sobre as ações que ocorrem em contextos historicamente configurados".

${ }^{9}$ Tradução do texto original: "Landscape is now clearly recognized as an essential component for town and country planning. More than remarkable sites and beautiful panorama, landscape is considered as the living environment, including ordinary landscapes where people live daily, and where economic activities are made" (Sauter et al., 2008, p. 7).
} 
Entretanto a questão que se coloca primeiramente é a de que no âmbito de uma política de ordenamento territorial, como instrumento referencial para as demais políticas públicas nas diferentes escalas espaciais, da cidade ao campo, do local ao regional, incluindo a política de desenvolvimento urbano, se mostra emergente a necessidade de revisar sua eficácia perante os desafios de redução das desigualdades econômicas e sociais, uma vez que: "a política do desenvolvimento urbano, a cargo do Poder Municipal, deve atender às funções sociais da cidade e ao bem-estar de seus habitantes (CR, art. 182). A questão nuclear é como fixar um valor social para a vida humana ordenada com base no chamado direito à cidade" (Carmo, 2000, p. 22; grifos originais).

Vê-se que no caso brasileiro há um crescente processo de fragmentação espacial, fazendo dos espaços urbanos, intraurbanos e interurbanos, bem como das zonas rurais, áreas amorfas, ininteligíveis, desarticuladas territorialmente, fragmentadas espacialmente, atribuindo-se frequentemente tal processo à ausência de integração entre as diversas políticas públicas setoriais e à desarticulação entre os diferentes atores e sujeitos institucionais, como bem explicitado por Peres \& Chiquito (2012):

A multiplicidade das políticas e sua falta de integração, associadas ao arranjo político-territorial do poder nacional acarretaram demandas conflitivas e a aparente fragmentação do território, dificultando a integração do desenvolvimento e um efetivo ordenamento territorial de cunho ambiental (Peres \& Chiquito, 2012, p. 72).

Tendo em vista esse contexto, intui-se que as políticas territoriais atualmente vigentes no Brasil, baseadas em um modelo instrumental legal de planejamento, têm desconsiderado seus efeitos na paisagem das cidades, re- fletindo-se nela o mesmo padrão sociopolítico do Estado capitalista neoliberal de matriz estritamente econômica, que lhe dá origem.

Assim, partindo da observação empírica da existência de uma "crise" da paisagem nas cidades, intui-se inicialmente que a dimensão de seu interesse público não tem sido apreendida e consequentemente não tem sido adotada como questão (issue) pelos atores do campo das políticas públicas, fragilizando e comprometendo o destino configuracional das cidades, subtraindo o direito dos cidadãos e da sociedade à preconizada qualidade de vida nas urbes.

Dessa forma, sugere-se superar os princípios de planejamento que majoritariamente têm sido empregados, como o clássico planejamento físico-territorial (blueprint planning ${ }^{10}$ ), base de pensamento do urbanismo modernista, e o system planning ${ }^{11}$, que surgiu entre as décadas de 1960 e 1970 em contraposição ao primeiro, estruturado na Teoria Geral dos Sistemas, bem como uma versão mais equilibrada surgida posteriormente aos dois primeiros, denominada de mix scannig desenvolvida por Etzione.

Toda essa forma de lidar como o planejamento urbano, conforme Souza (2013, p. 133), “[...] se volta exclusivamente para a adequação do meio a fins preestabelecidos [...]", tendo como enfoque o processo (procedural), no qual "[...] o debate não gira em torno da natureza da realidade, das prioridades do planejamento ou dos problemas concretos a serem superados (isto é, do objeto), mas exclusivamente em torno dos procedimentos (vale dizer, do método)" (Souza, 2013, p. 134), marcando um planejamento estritamente regulatório (regulative planning)".

Como resultado dessas práticas e não obstante toda a normatização existente envolvendo o desenho das cidades, abarcada pelo corolário de leis, planos e

\footnotetext{
${ }^{10}$ Segundo Souza (2013, p. 123): "Tipicamente trata-se de planos nos quais se projeta a imagem desejada em um futuro mais ou menos remoto - nos estilo 'a cidade $\mathrm{x}$ daqui a vinte anos' - funcionando o plano como um conjunto de diretrizes a serem seguidas e metas a serem perseguidas (quanto aos usos da terra, ao traçado urbanístico, ao controle da expansão e do adensamento urbanos, à provisão de áreas verdes e ao sistema de articulação)."
} 
políticas urbanas que orientam as ações físicas sobre o território, observa-se que as paisagens como outputs, muitas vezes, revelam-se enquanto mosaicos ininteligíveis ou, no mínimo, de difícil apreensão por parte dos cidadãos. No interior dessa percepção evidencia-se que:

a edificação indiscriminada, a poluição visual dos espaços públicos ou a ocupação indevida do espaço coletivo são exemplos de fatores que podem acarretar a descaracterização ou até mesmo o desaparecimento da paisagem urbana referencial. É a importância do cenário da cidade e a necessidade de sua proteção no cotidiano das políticas administrativas municipais que se pretende aqui salientar (Vizzoto, 2012, p. 328).

Nesse sentido, as cidades e as paisagens que as identificam podem ser lidas como produtos ou reflexos diretos das escolhas e diretrizes políticas e das políticas públicas. Assim, a paisagem deveria ser objeto de uma política pública específica, empreendida pelo Estado, atinente aos anseios da coletividade. Em contrapartida, isso significa dizer que:

o desenvolvimento de práticas privadas deve estar fundado na orientação de políticas públicas, as quais teriam a vocação de efetivamente realizar os objetivos básicos previstos no capítulo de meio ambiente tendo presentes os demais princípios norteadores da sociedade brasileira. Pela orientação do comportamento coletivo, garante-se uma prática privada gratificante ao investidor e à sociedade (Derani, 1997, p. 160).

\subsection{A paisagem na perspectiva de uma política pública especifica}

Verifica-se, tanto no plano internacional quanto no nacional, o nascimento de institutos documentais que estabelecem recomendações advindas de convenções entre atores governamentais e privados, com o foco na paisagem, na perspectiva de estabelecer uma política pública que a considere no âmbito do ordenamento territorial, visando promover o desenvolvimento de forma menos localizada e mais regionalizada e multiescalar.

Como exemplo ilustra-se a Convenção Europeia da Paisagem $(\mathrm{CEP})^{12}$, tendo como signatários os Estados-membros do Conselho da Europa, na qual se anunciam algumas diretrizes e pressupostos, estabelecendo as prerrogativas da política de paisagem para o continente europeu. A CEP objetiva que os diversos países adotem a paisagem como tema integrante de suas políticas territoriais de desenvolvimento, reconhecendo-a juridicamente como elemento de planejamento físico-espacial ${ }^{13}$.

Fazendo uso do destaque ofertado por Neto (2010), em referência a Michel Prieur, explicita-se que "[...] os países que se submeteram à referida convenção [CEP] foram consentes em dois pontos para a sua aprovação: a paisagem é algo dinâmico e complexo e não algo estático e simples; a paisagem é bem difuso e deve preservar a diversidade em geral" (Prieur, 2005 apud Neto, 2010, p. 35).

Decorrente das recomendações da CEP é editada na Catalunha, Espanha, a Lei n. 8/2005 de Protecció, Gestió i Ordenació del Paisatge, com a finalidade de

\footnotetext{
${ }^{12}$ Primeiro tratado internacional especificamente sobre a paisagem, editada em Florença, em 2000, e em vigor desde 2004.

${ }^{13}$ Destacamos, da CEP, em “Capítulo $1^{\circ}$. Definições”: “b) 'Política da paisagem’ designa a formulação pelas autoridades públicas competentes de princípios gerais, estratégias e linhas orientadoras que permitam a adopção de medidas específicas tendo em vista a protecção, a gestão e o ordenamento da paisagem; [...] e) 'Gestão da paisagem' designa a acção visando assegurar a manutenção de uma paisagem, numa perspectiva de desenvolvimento sustentável, no sentido de orientar e harmonizar as alterações resultantes dos processos sociais, económicos e ambientais; $\mathrm{f}$ ) 'Ordenamento da paisagem' designa as acções com forte carácter prospectivo visando à valorização, à recuperação ou à criação de paisagens”.
} 
"[...] equilibrar o desenvolvimento econômico e a qualidade urbana do ambiente, tendo em conta o valor o patrimonial, cultural e econômico"14.

Disso, pode-se intuir como enfoque dessa diretriz a necessidade de se compreender o desenvolvimento econômico articulado ao meio ambiente equilibrado, uma vez que, assim,

[...] tende a reconstruir as bases estruturantes da relação dialética entre a prática econômica e a reprodução dos sistemas ecológicos, modelando novos conceitos, métodos, princípios e instrumentos que possam orientar a condução de políticas públicas destinadas a promover um permanente ajustamento entre economia e meio ambiente (Duarte, 2004, p. 519).

Outro exemplo em âmbito internacional é a recente iniciativa de formulação de uma "Política Nacional de Arquitectura e Paisagem para Portugal", conforme publicado no Diário Oficial desse país, em 10 de julho de $2013^{15}$. Tal iniciativa já é fruto, na verdade, de alguns desdobramentos da própria política urbana nacional de Portugal, na tentativa de aplicação da CEP nos planos diretores municipais, fomentado pela Direção Geral de Ordenamento do Território e Desenvolvimento Urbano - DGOTDU: em número significativo de casos, essa implementação está a ser feita através dos respectivos sistemas de gestão territorial, sendo que os países onde tal se verifica maior sucesso parecem ser aqueles onde existe uma capacidade do poderes regionais e locais assumirem a CEP como doutrinária e a paisagem com fator de desenvolvimento territorial e de aprofundamento da cultural democrática [...] (Portugal, 2011, p. 8).

Nesse sentido, a Sociedad Colombiana de Arquitectos Paisajistas desenvolveu a Carta Colombiana del Paisaje (2010, tradução nossa), sob a premissa de que "nas últimas décadas a sociedade tem tomado consciência de que a capacidade tecnológica e a pressão demográfica representam uma ameaça para numerosos recursos de caráter tanto natural como cultural, entre eles a paisagem [...]"'16.

Toda essa repercussão, para Neto (2010, p. 30), "significa que, internacionalmente, a paisagem é em toda parte um elemento importante da qualidade de vida da coletividade, pois se constatou que ela desempenha importantes funções de interesse público, nos campos cultural, social e ambiental".

No Brasil, mais recentemente, foi elaborada a Carta Brasileira da Paisagem, levada a cabo pela Associação Brasileira dos Arquitetos Paisagistas (ABAP), na qual se propõe um conjunto de doze princípios ${ }^{17}$,

\footnotetext{
${ }^{14}$ Lei n. 8, de 8 de junho de 2005, de Protecció, Gestió i Ordenació del Paisatge. Tradução do autor, do trecho original: “Aquesta llei vetlla per la protecció del paisatge i defineix els instruments dels quals el Govern es dota per a reconèixer-ne jurídicament els valors i per a promoure actuacions per a conservar-lo i millorar-lo. Així, aquesta llei té per objectiu fer compatible el desenvolupament econòmic i urbanístic amb la qualitat de l'entorn, atenent els valors patrimonials, culturals i econòmics". Fonte: Diari Oficial de la Generalitat de Catalunya, n. 4407 - 16.6.2005. Disponível em: http:/www.catpaisatge.net/cat/cartes.php. Acesso em: 31.07.2014.

${ }^{15}$ Publicado no Diário da República de Portugal (Diário da República, 2a. Série- n. ${ }^{\circ} 131-10$ de julho de 2013). Disponível em: http://www. arquitectos.pt/index.htm?no=2020494377. Acesso em: 01.11.2013.

${ }^{16}$ Tradução do autor, do trecho original da Carta Colombiana da Paisagem (2010): "En las últimas décadas la sociedad ha tomado conciencia de que la capacidad tecnológica y la presión demográfica representan una amenaza para numerosos recursos de carácter tanto natural como cultural, entre ellos el paisaje [...]". Disponível em: www.sapcolombia.org/pdf/La_CartaColombiana_del_Paisaje_2010.pdf. Acesso em: 05.01.2015.

${ }^{17}$ Os doze princípios da Carta Brasileira da Paisagem: "1- a paisagem e seu papel coletivo; 2- reconhecimento das paisagens brasileiras e seus ecossistemas; 3- as relações entre a paisagem e a população: paisagens culturais brasileiras; 4- a paisagem como instrumento de planificação do desenvolvimento sustentável do país; 5- a paisagem e seu valor econômico para a sociedade brasileira; 6- a necessidade do respeito e da preservação de nossas paisagens; 7- o direito democrático à qualidade ambiental e paisagística; 8- os princípios locais e nacionais para gestão efetiva da paisagem no Brasil; 9- a necessidade da visão integrada para os projetos e políticas governamentais; 10- intercâmbios paisagísticos na América através dos grandes compartimentos territoriais de nossas paisagens; 11- as paisagens urbanas em degradação e as relações com o crescimento populacional nas metrópoles - problema a ser enfrentado com novas visões tecnológicas; 12- a realidade das áreas rurais e a necessidade de valorização e restauração de paisagens pioneiras." Fonte: Abap- Associação Brasileira dos Arquitetos Paisagistas. Carta Brasileira da Paisagem. Rio de Janeiro, 2012. Disponível em: www.caubr.gov.br/anexos/noticias/CARTA_BRASILEIRA_DA_PAISAGEM.pdf. Acesso em: 05.01.2015.
} 
que objetivam a adoção da questão da paisagem pelas políticas urbanas. Documento este referenciado tanto na CEP quanto estimulado pela Carta de Bagé ${ }^{18}$, ou Carta da Paisagem Cultura Brasileira, de 2007, servindo ainda como reflexão preparatória para a elaboração da Carta Latino-Americana da Paisagem (a exemplo do que aconteceu no continente europeu), bem como atinente aos objetivos da Convenção Global da Paisagem, proposta pela IFLA ${ }^{19}$.

Com esses institutos documentais a paisagem é lançada e formulada na condição de objeto e tema importante, de interesse público, surgindo como questão de política pública, reclamando seu reconhecimento nas agendas governamentais, e como objeto do direito.

\section{Considerações finais}

Observa-se que a paisagem tem sido negligenciada pelo Estado, no âmbito do planejamento territorial e urbano. Isso provavelmente em razão de que o princípio da supremacia do interesse público, como lógica republicana e constitucional, se encontra invertido na prática política brasileira, pela preponderância do interesse privado nos processos de desenvolvimento das cidades, regida predominantemente pela noção de desenvolvimento econômico, em detrimento de um desenvolvimento social.
Constata-se, entretanto, que a paisagem se apresenta concretamente como fenômeno e objeto de interesse público, ao ser explicitada a partir de sua dimensão sociopolítica e, ao ser evidenciada como um problema político, instrumentaliza a formulação de uma política pública de desenvolvimento urbano atinente à mesma.

Para tanto, observa-se a necessidade de problematizar a relação do sujeito com a natureza no processo de artificialização que é a construção da cidade, como algo dinâmico e em constante processo de transformação, o que impacta sobremaneira a paisagem percebida, ou mesmo a relação dos seres sociais com atores/agentes na construção política do espaço da cidade como lócus de encontro, como lugar de morada.

Por fim, verifica-se que o surgimento de propostas de políticas públicas de paisagem evidencia a emergência desse tema como relevante problema político, necessitando ser reconhecido pelo Estado e por toda a sociedade como um direito, no qual a paisagem pode cumprir importante papel de conexão, intersubjetiva, entre os seres sociais de uma dada comunidade, sob o risco de se ver comprometida a própria criação da Cidade como espaço de relações humanas.

Por meio da compreensão da paisagem como um direito social, acredita-se, é possível reconectar elos perdidos do ser humano com a natureza, tanto a natureza biológica quanto da cidade como natureza eminentemente social e política.

\footnotetext{
${ }^{18}$ A Carta de Bagé foi redigida na cidade de Bagé, no Rio Grande do Sul, em 17 de agosto de 2007, sob a iniciativa do Instituto do Patrimônio Histórico e Artístico Nacional, quando se passou a adotar o conceito de paisagem cultural desenvolvido pela Unesco em 1992. Disponível em: http://portal.iphan.gov.br/portal/baixaFcdAnexo.do?id=895. Acesso em: 31.07.2014.
}

${ }^{19}$ IFLA - Internacional Federation of Landscape Architects. 


\section{Referências}

Bauman, Z. Capitalismo parasitário. Rio de Janeiro: Jorge Zahar, 2010.

Berman, M. Tudo o que é sólido desmancha no ar: a aventura da modernidade. São Paulo: Schwarcz, 1986.

Berque, A. Paisagem marca, paisagem matriz. Elementos da problemática para uma geografia cultural. Ecole dês Hautes Etudes en Sciences Sociales, Paris. In: Corrêa, R.L.; Rosendhal, Z. (Org.). Paisagem, tempo e cultura. Rio de Janeiro, 1998, p. 84-91.

Bobbio, N. Dicionário de política. Brasília: Universidade de Brasília, 1998.

Brasil. Ministério da Integração Nacional. Para pensar uma política de ordenamento territorial. In: Anais da Oficina sobre a Política Nacional de Ordenamento Territorial. Brasília: MI, 2005.

Carmo, J. V. do. A tutela de interesses difusos e o direito ao bem-estar urbano. Revista Direito, 4(8), 15-34, 2000. Disponível em: http:/www.camara.rj.gov.br/setores/proc/revistaproc/ revproc2000/revdireito2000b/art_tutelainteres.pdf. Acesso em: 29.12.2014.

Derani, C. Direito ambiental econômico. São Paulo: Editora Max Limonad, 1997.

Duarte, C. de S. As novas exigências do Direito ambiental. In: Leite, J. R. M.; Filho, N. de B. B. (Org.). Direito Ambiental contemporâneo. Barueri, SP: Manole, 2004, p. 503-530.

Elias, N. A sociedade dos indivíduos. Rio de Janeiro: Jorge Zahar, 1994.

Fagúndez, P. R. A. O significado da modernidade. In: Leite, J. R. M.; Filho, N. de B. B. (Org.). Direito ambiental contemporâneo. Barueri, SP: Manole, 2004, p. 205-246.

Howlett, M.; Ramesh, M.; Perl, A. Política pública. Seus ciclos e subsistemas. Uma abordagem integral. Rio de Janeiro: Elsevier, 2013.

Jorge, A. P.; Gentil, P. A. B. Tutela jurídica da paisagem urbana: rumo à defesa do direito à qualidade de vida. In: Anais do XVIII Congresso Nacional do CONPEDI. São Paulo, 2296-3013, 2009. Disponível em: http://www.publicadireito. com.br/conpedi/manaus/arquivos/Anais/sao_paulo/2623.pdf. Acesso em: 27.12.2014.
Leite, J. R. M.; Ayala, P. de A. Transdisciplinaridade e a proteção jurídico-ambiental em sociedades de risco: direito, ciência e participação. In: Leite, J. R. M.; Filho, N. de B. B (Org.). Direito Ambiental contemporâneo. Barueri, SP: Manole, 2004, p. $99-125$.

Mazzilli, H. N. A defesa dos interesses difusos em juízo. São Paulo: Saraiva, 2007.

Neto, A. Z. Direito à paisagem. Revista Internacional de Direito e Cidadania, 8, 29-37, 2010. Disponível em: http://www.reid. org.br/arquivos/00000202-03-antonio_zanollo.pdf. Acesso em: 28.12.2014.

Ost, F. A natureza à margem da lei. A ecologia à prova do direito. Lisboa: Instituto Piaget, 1995.

Peres, R. B.; Chiquito, E. de A. Ordenamento territorial, meio ambiente e desenvolvimento regional. Novas questões, possíveis articulações. Revista Brasileira de Estudos Urbanos e Regionais, 14(2), 2012.

Portugal. DGOTDU- Direcção Geral de Ordenamento do Território e Desenvolvimento Urbano. A paisagem na revisão dos PDM: orientações para a implementação da Convenção Europeia da Paisagem no âmbito municipal: Documentos de orientação 02/2011. Lisboa, 2011.

Roca, Z.; Oliveira, J. Políticas públicas e nexo paisagem-identidade-desenvolvimento: um contributo para o estado da arte. In: Actas do XII Colóquio Ibérico de Geografia. Porto: Faculdade de Letras (Universidade do Porto), 2010. Disponível em: http://web.letras.up.pt/xiicig/publicacao.aspx. Acesso em: 28.12.2014.

Santos, M. A Urbanização brasileira. São Paulo: Editora Universidade de São Paulo, 2013.

Santos, M. 1992: A redescoberta da Natureza. (Aula inaugural da Faculdade de Filosofia, Letras e Ciências Humanas, em 10 de março de 1992). São Paulo: Universidade de São Paulo, 1992.

Sauter, A.; Ormaux, S.; Tourneux, F. P. Landscape and public policies: evaluation and indices. In: The International Conference of Territorial Intelligence- "Tools and methods of Territorial Intelligence”. Besançon, França: 2008, p. 1-7. Disponível em: www.territorial-inteligence.eu/index.php/ besancon08/Sauter. Acesso em: 05.01.2015. 
Serrão, A. V. Filosofia da paisagem. Estudos. Lisboa: Universitas Oliponensis. Centro de Filosofia da Universidade de Lisboa, 2013.

Simmel, G. Filosofia da paisagem. Covilhã: Lusofia, 2009.

Simmel, G. A metrópole e a vida mental. In: Velho, O. G (Org.). O fenômeno urbano. Rio de Janeiro: Zahar Editores, 1973.

Souza, M. L. de. Mudar a cidade. Uma introdução crítica ao planejamento e à gestão urbanos. Rio de Janeiro: Bertrand Brasil, 2013.
Steinberger, M. Território, ambiente e políticas públicas espaciais. Brasília: Editora Paralelo 15, 2006.

Vizzotto, A. T. A paisagem urbana como objeto jurídico. Revista Direito, Cultura e Cidadania, 2(1), 2012. Disponível em: http:// facos.edu.br/publicacoes/revistas/direito_cultura_e_cidadania/ marco_2012/pdf/a_paisagem_urbana_como_objeto_juridico. pdf. Acesso em: 28.12.2014. 